\title{
New North American Chrysauginae (Pyralidae) described by E.D. Cashatt
}

\author{
M. Alma Solis ${ }^{1, \dagger}$, Everett D. Cashatt ${ }^{2, \ddagger}$, Brian G. Scholtens ${ }^{3, \S}$ \\ I MAS, Systematic Entomology Laboratory, USDA, National Museum of Natural History, P.O. Box 37012, \\ MRC 168, Washington, DC USA 20013-7012 2 EDC, Everett D. Cashatt, Illinois State Museum, 1011 E. \\ Ash Street, Springfield, IL 62703, USA 3 BGS, Brian G. Scholtens, Biology Department, College of Charle- \\ ston, Charleston, SC, USA 29424 \\ † http://zoobank.org/1D7A6EA3-D848-404F-82C8-A3EFB71AE123 \\ † http://zoobank.org/67A38004-10EF-45BB-A1ED-6BE4FF24463E \\ § http://zoobank.org/87F27EFF-C20F-49B8-B7F5-B1239FD00FF5 \\ Corresponding author:Alma M. Solis (alma.solis@ars.usda.gov)
}

Academic editor: E. van Nieukerken | Received 22 May 2013 | Accepted 10 September 2013 | Published 22 October 2013

http://zoobank.org/4D6C8009-B32C-4FAE-8DA9-E21AD5FEB9D8

Citation: Solis AM, Cashatt ED, Scholtens BG (2013) New North American Chrysauginae (Pyralidae) described by E.D. Cashatt. ZooKeys 344: 55-71. doi: 10.3897/zookeys.344.5609

\begin{abstract}
A Ph.D. dissertation completed by E.D. Cashatt in 1968 entitled "Revision of the Chrysauginae of North America" does not meet the criteria of publication so the new taxa described therein are not available per the International Code of Zoological Nomenclature. In order to validate the taxa proposed in that document we formally describe and illustrate the following: Arta brevivalvalis Cashatt, sp. n., Heliades lindae Cashatt, sp. n., Paragalasa Cashatt, gen. n., Paragalasa exospinalis Cashatt, sp. n., and Penthesilea sacculalis baboquivariensis Cashatt, subsp. $\mathbf{n}$. We summarize other taxonomic actions proposed in the dissertation and those proposed by subsequent authors. We provide the current nomenclatural status with the literature citation of the paper in which the current status was proposed. A lectotype is designated for $\mathrm{Cly}$ donopteran tecomae. Adult holotypes and associated labels, and genitalia of paratypes are newly illustrated.
\end{abstract}

\section{Keywords}

Chrysauginae, Pyralidae, North America, Campsis radicans

Copyright Alma M. Solis et al. This is an open access article distributed under the terms of the Creative Commons Attribution License 3.0 (CC-BY), which permits unrestricted use, distribution, and reproduction in any medium, provided the original author and source are credited. 


\section{Introduction}

Cashatt's (1968) Ph.D. dissertation entitled "Revision of the Chrysauginae of North America" included numerous nomenclatural acts that are unavailable according to the most recent International Code of Zoological Nomenclature (ICZN 1999). Cashatt distributed only two copies of his dissertation (Cashatt 1968) on North American Chrysauginae: the mandatory one at Catholic University of America, and one at the library at The Natural History Museum, London, thus the entire dissertation does not constitute a published work (ICZN 1999, p. 6, Article 8). In 1969, Dissertation Abstracts International published and widely distributed the abstract of this dissertation and offered copies of the dissertation for sale. Whether the dissertation (Cashatt 1968) minimally meets criteria for what constitutes a published work (i.e. ICZN, Article 8, p. 6) is ambiguous (Haman and Huddleston 1980). As an example, Fletcher and Nye (1984) considered the names Basacallis and Paragalasa available stating: "Cashatt's revision was originally a dissertation submitted to the Catholic University of America for the degree of Doctor of Philosophy. It was published on paper by University Microfilms International (UMI) and has been available since June 1969 when it was advertised for sale in Diss. Abst. Int. (B) 29(12): 4696." Fletcher and Nye (1984) include these genera only because a copy was available to them at The Natural History Museum in London. The work was not accessible, however, to other institutions or scientists in the world short of visiting London or Catholic University. In contrast, Cashatt believed his dissertation to be unpublished, and he wrote a formal description of Basacallis in 1984. In our opinion the ICZN Recommendation (ICZN 199, p. 9, 8A) that dissemination should be in scientific journals and series, precludes the assumption of two copies constituting wide availability. In addition, the Code recommends that new names be sent to Zoological Record, but in this case they were not. So while the abstract published by UMI was widely available, we propose that the nomenclatural acts in the rest of the dissertation are not available.

In this work we make available by publication the taxa described in the dissertation by Cashatt (1968). We replicate the text from the dissertation with minimal editing (only as needed) from the dissertation for Arta brevivalvalis Cashatt, sp. n., Heliades lindae Cashatt, sp. n., Paragalasa Cashatt, gen. n., Paragalasa exospinalis Cashatt, sp. $\mathrm{n}$., and Penthesilea sacculalis baboquivariensis Cashatt, subsp. $\mathrm{n}$. We update the terminology of the genitalia, but not that of the wing venation. We attribute authorship of all taxa to E. D. Cashatt. We include redescriptions of the monotypic Penthesilea Ragonot, 1891 and Penthesilea sacculalis sacculalis Ragonot, 1891 because the new subspecies description would have been difficult to comprehend otherwise. We provide illustrations of the adults and genitalia (i.e., not the illustrations from the dissertation) from the type specimens located in the National Museum of Natural History, Washington, DC (USNM). We also summarize other taxonomic actions (Table 1) by Cashatt (1969) and the current status of taxa in two major taxonomic lists, the Moths of America north of Mexico (Munroe 1983), and the Atlas of Neotropical Lepidoptera (Solis et al. 1995). Cashatt (1968) used the following acronyms for collections where 
material is deposited: AMNH (American Museum of Natural History, New York, USA), CNC (Canadian National Collection, Ottawa, Canada), CU (=CUIC, Cornell University Insect Collection, Ithaca, New York, USA), USNM (=NMNH, National Museum of Natural History, Washington, DC, USA).

\section{Taxonomic actions (see Table I)}

In his abstract, Cashatt (1969) stated, "Clydonopteron Riley is reinstated as a genus separate from Salobrena Walker"; it had been synonymized by Hampson (1897). The revised status of Salobrena is valid and attributable to Cashatt (1969). In the dissertation, Cashatt (1968) also synonymized C. tecomae Riley, 1880 as a junior synonym of Pyralis sacculana Bosc, [1800]. This synonymy was independently discovered and published by Miller and Becker (1989) as a new synonymy (see Landis et al. 1992); so the correct attribution of the status of $C$. tecomae as a junior synonym of $P$. sacculana is Miller and Becker (1989). Miller and Becker (1989) also newly combined P. sacculana in Clydonopteron; so the correct attribution for the new combination Clydonopteron sacculana is Miller and Becker (1989). In the dissertation Cashatt (1968) stated he was unable to locate the type specimen of $P$. sacculana, but based on illustrations he was "convinced it is conspecific with tecomae." He located two female types of C. tecomae without locality data, but labeled "1878, USNM Type No. 366" in the USNM. He designated one of these specimens as the lectotype and the other as the paralectotype. The lectotype and paralectotype are newly designated here with attribution to Cashatt, and labeled as such in the USNM. Cashatt noted that Riley (1880) also provided a description of the life history; eggs are laid in seedpods of trumpet vine (Campsis radicans (L.) Seem. ex Bureau, Bignoniaceae) where larvae and pupae develop. Landis et al. (1992) published more on the biology of this species and described the egg stage. In Landis et al. (1992) EDC mistakenly used the year 1969 for the date of his dissertation in the References Cited.

Cashatt (1984) described the new genus Basacallis Cashatt and designated Parachma tarachodes Dyar, 1914, as the type species, and that is the correct attribution for availability and validity. Solis et al. (1995) correctly attributed this genus to Cashatt, but used the incorrect date of 1969, instead of 1984 .

In the dissertation Cashatt (1968) synonymized the following genera and transferred and/or synonymized type species. Artopsis Dyar, 1908 was synonymized with Parachma Walker, [1866] in the checklist (Cashatt 1968), and it did not appear in the abstract (Cashatt 1969). Attribution for this synonymy should be Barnes and McDunnough (1917) where it first appeared, although it was not stated explicitly. Cashatt (1968) synonymized the type species, Artopsis borregalis Dyar, 1908 with Parachma ochracealis Walker, [1866], and published this new synonymy in Cashatt (1984), but Solis et al. (1995) revised the status of borregalis, considering it a valid species. Herein we synonymize $A$. borregalis with $P$. ochracealis, revised status, and attribute this action to Cashatt. In addition, Cashatt (1968) listed 1909 as the date of publication for 
Table I. Nomenclatural acts and attributions relating to taxa in Cashatt (1968). See text for more information.

\begin{tabular}{|c|c|c|}
\hline Taxon name & Action & Attribution \\
\hline Salobrena Walker, 1863 & Revised status as genus & Cashatt (1969) \\
\hline Clydonopteron tecomae Riley, 1880 & Synonym of Pyralis sacculana & Miller and Becker (1989) \\
\hline Pyralis sacculana Bosc, [1800] & Combination in Clydonopteron Riley & Miller and Becker (1989) \\
\hline Basacallis Cashatt, 1984 & Genus description & Cashatt (1984) \\
\hline Artopsis Dyar, 1908 & Synonym of Parachma Walker & $\begin{array}{l}\text { Barnes and } \\
\text { McDunnough (1917) }\end{array}$ \\
\hline Artopsis borregalis Dyar, 1908 & New revised status of Parachma ochracealis & Present paper \\
\hline Polloccia Dyar, 1910 & Synonym of Acallis Ragonot & Cashatt (1969) \\
\hline alticolalis Dyar, 1910 & Combination in Acallis Ragonot & Solis et al. (1995) \\
\hline Balidarcha Dyar, 1914 & Synonym of Anemosella Dyar & Cashatt (1969) \\
\hline cuis Dyar, 1914 & Synonym of viridalis B.\&McD. & Munroe (1983) \\
\hline cuis Dyar, 1914 & Combination in Anemosella Dyar & Munroe (1983) \\
\hline Xantippides Dyar, 1908 & Synonym of Arta Grote & Cashatt (1969) \\
\hline descansalis Dyar, 1908 & Synonym of Arta epicoenalis Ragonot & Munroe (1983) \\
\hline descansalis & Combination in Arta Grote & Munroe (1983) \\
\hline centralis Dyar, 1910 & New synonym of Acallis gripalis Hulst & Present paper \\
\hline polingalis B.\& B., 1926 & New synonym of Anemosella basalis Dyar & Present paper \\
\hline beatifica Dyar, 1921 & New synonym of Arta epicoenalis Ragonot & Present paper \\
\hline beatifica Dyar, 1921 & New combination in Arta Grote & Present paper \\
\hline uranides Dyar, 1921 & New synonym of Heliades mulleolella Hulst & Present paper \\
\hline uranides Dyar, 1921 & New combination in Heliades Ragonot & Present paper \\
\hline $\begin{array}{l}\text { Heliades huachucalis Haimbach, } \\
1915\end{array}$ & New revised status as species & Present paper \\
\hline $\begin{array}{l}\text { Negalasa rubralis B. \& McD., } \\
1913\end{array}$ & Revised status as species & Solis et al. (1995) \\
\hline Arta brevivalvalis & New species & Present paper \\
\hline Heliades lindae & New species & Present paper \\
\hline Paragalasa & New genus & Present paper \\
\hline Paragalasa exospinalis & New species & Present paper \\
\hline Penthesilea sacculalis sacculalis & New revised status as subspecies & Present paper \\
\hline $\begin{array}{l}\text { Penthesilea sacculalis } \\
\text { baboquivariensis }\end{array}$ & New subspecies & Present paper \\
\hline
\end{tabular}

Artopsis and A. borregalis which should have been 1908, but the confusion of the year is due to the publication of volume 10 of the Proceedings of the Entomological Society of Washington in two different years; issues 1 and 2 (pp. 1-118) in 1908 and issues 3 and 4 (pp. 119-221) in 1909.

Cashatt (1968) synonymized Polloccia [misspelled in the dissertation as Pollocia] Dyar, 1910 with Acallis Ragonot, 1891 and transferred the type species, Polloccia alticolalis Dyar, 1910 to Acallis. The abstract (Cashatt 1969) mentions this generic synonymy so the correct attribution for the status of Polloccia as a junior synonym of 
Acallis is Cashatt (1969). The abstract (Cashatt 1969) did not transfer the type species, but Solis et al. (1995) newly combined P. alticolalis in Acallis, so Solis et al. (1995) is the correct attribution.

Cashatt (1968) synonymized Balidarcha Dyar, 1914 with Anemosella Dyar, 1914 and the generic synonymy does appear in the abstract (Cashatt 1969), so the correct attribution of the status of Balidarcha as a junior synonym of Anemosella is Cashatt (1969). Cashatt (1968) synonymized Balidarcha cuis, Dyar, 1914 with Anemosella viridalis Barnes \& McDunnough, 1912. The abstract (Cashatt 1969) did not transfer or synonymize the type species, but Munroe (1983) treated B. cuis as a new synonym, and as a new combination although not stated, so the correct attribution for the status of $B$. cuis as a junior synonym of $A$. viridalis and a new combination in Anemosella is Munroe (1983). Balidarcha cuis was also treated as a synonym by Solis et al. (1995).

Cashatt (1968) synonymized Xantippides Dyar, 1908 with Arta Grote, 1875 and transferred the type species, Xantippides descansalis Dyar, 1908 as a synonym of Arta epicoenalis Ragonot, 1891. The generic synonymy appears in the abstract (Cashatt 1969), so the correct attribution of the status of Xantippides as a junior synonym of Arta is Cashatt (1969). The transfer of the type species does not appear in the abstract (Cashatt 1969). Munroe (1983) published the synonymy of $X$. descansalis as a new combination and new synonymy, so the correct attribution for the status of $X$. descansalis as a new combination and junior synonym of $A$. epicoenalis is Munroe (1983).

Cashatt (1968) synonymized the following species in his dissertation, but they do not appear in the abstract (Cashatt 1969) so we newly synonymize these species below. Cashatt (1968) synonymized Acallis centralis Dyar, 1910 with Acallis gripalis Hulst, 1886. Munroe (1983) and Solis et al. (1995) treated $A$. centralis as a valid species of Acallis. Herein we synonymize $A$. centralis with $A$. gripalis, new synonymy, with attribution to Cashatt.

Cashatt (1968) synonymized Anemosella polingalis [misspelled in the dissertation as pollingalis], Barnes and Benjamin 1926 with Anemosella basalis Dyar, 1914. It was treated as a valid species by Munroe (1983) and Solis et al. (1995). Herein we synonymize $A$. polingalis with $A$. basalis, new synonymy, with attribution to Cashatt.

Cashatt (1968) synonymized and combined Xantippe beatifica Dyar, 1921 with Arta epicoenalis Ragonot, 1891. It was treated as a valid species of Xantippe by Munroe (1983) and Solis et al. (1995). Herein we synonymize $X$. beatifica with $A$. epicoenalis, new combination, new synonymy, with attribution to Cashatt.

Cashatt (1968) synonymized and combined Xantippe uranides Dyar, 1921 with Heliades mulleolella (Hulst, 1887). It was treated as a valid species in Xantippe in Munroe (1983) and Solis et al. (1995). Herein we synonymize X. uranides with $H$. mulleolella, new combination, new synonymy, with attribution to Cashatt.

Haimbach (1915) described Pyrausta huachucalis, but McDunnough (1939) revised its status as a junior synonym of Heliades mulleolella Hulst, 1887. Munroe (1983) and Solis et al. (1995) also treated $H$. huachucalis as a junior synonym of $H$. mulleolella. Cashatt (1968) elevated $H$. huachucalis to species stating: “...this western 
species is distinct from the eastern one." Herein we elevate $H$. huachucalis to species status, revised status, with attribution to Cashatt.

Negalasa rubralis Barnes \& McDunnough, 1913 was treated as a subspecies of $N$. fumalis by Munroe (1983) but was not clearly stated to be a revised status; it is historically interesting to note that Cashatt (1968) did the same thing. Negalasa rubralis was elevated back to species by Solis et al. (1995), but again it was not clearly stated to be a revised status. Due to the ambiguity of its status, we are leaving this status as determined by Solis et al. (1995).

\section{Taxon descriptions}

Arta brevivalvalis Cashatt, sp. n.

http://zoobank.org/BC60CF21-AF03-4025-B272-251827BA2B87

http://species-id.net/wiki/Arta_brevivalvalis

Figs 1, 5-7

Description. Head. Labial palpus reddish-brown laterad, inner surface ochreous; frons and vertex light reddish-brown to purplish; occiput tan to ochreous.

Thorax. Upper surface reddish-brown to tan, under surface darker. Forewing reddish- to purplish-brown with ochreous antemedial and postmedial lines; antemedial line irregular and extending obliquely from two-thirds costa to nearly one-half hind margin; postmedial line irregular and directed slightly inward near costa, extending from three-fifths costa to near anal angle; distance between the two lines greater at costa than at hind margin; fringe ochreous; under surface brown, purplish-red near costa and outer margin. Hind wing grayish-brown with ochreous fringe; underside purplish-red near costa and outer margin, a short postmedial line from costa fading inward. Legs purplish-brown with mid femur, midtibia, and inner surface of hind leg ochreous.

Abdomen. Ochreous dorsad, reddish-brown ventrad, terminal fringe ochreous.

Male genitalia. Uncus broad and shovel-shaped; tegumen narrow, pedunculus unmodified; vinculum broad, saccus not narrowly produced anteriad as in statalis, but rounded; juxta acutely hooked dorsad near base with apex directed slightly dorsad; valva as in statalis except shorter with a broader base, apex unidentate; phallus long and slender with apex flattened without a coecum or cornutus.

Female genitalia. Ovipositor moderately enlongate, papillae anales small and unilobate; posterior apophysis extremely short; anterior apophysis short as in statalis; ostium bursae wide; lamella antevaginalis broad and V-shaped, opening near anterior margin of eighth sternite; bursa copulatrix simple with inception of ductus seminalis below antrum; without a signum.

Type data. The type specimens are located as noted below. The male holotype is from Palmerlee, Arizona (no other data given) and is labeled as the holotype. Fiftythree male and twenty-two female paratypes from UNITED STATES: ARIZONA are labeled as follows: two females, Catalina Mts., no date given, Oslar Coll. (USNM); 

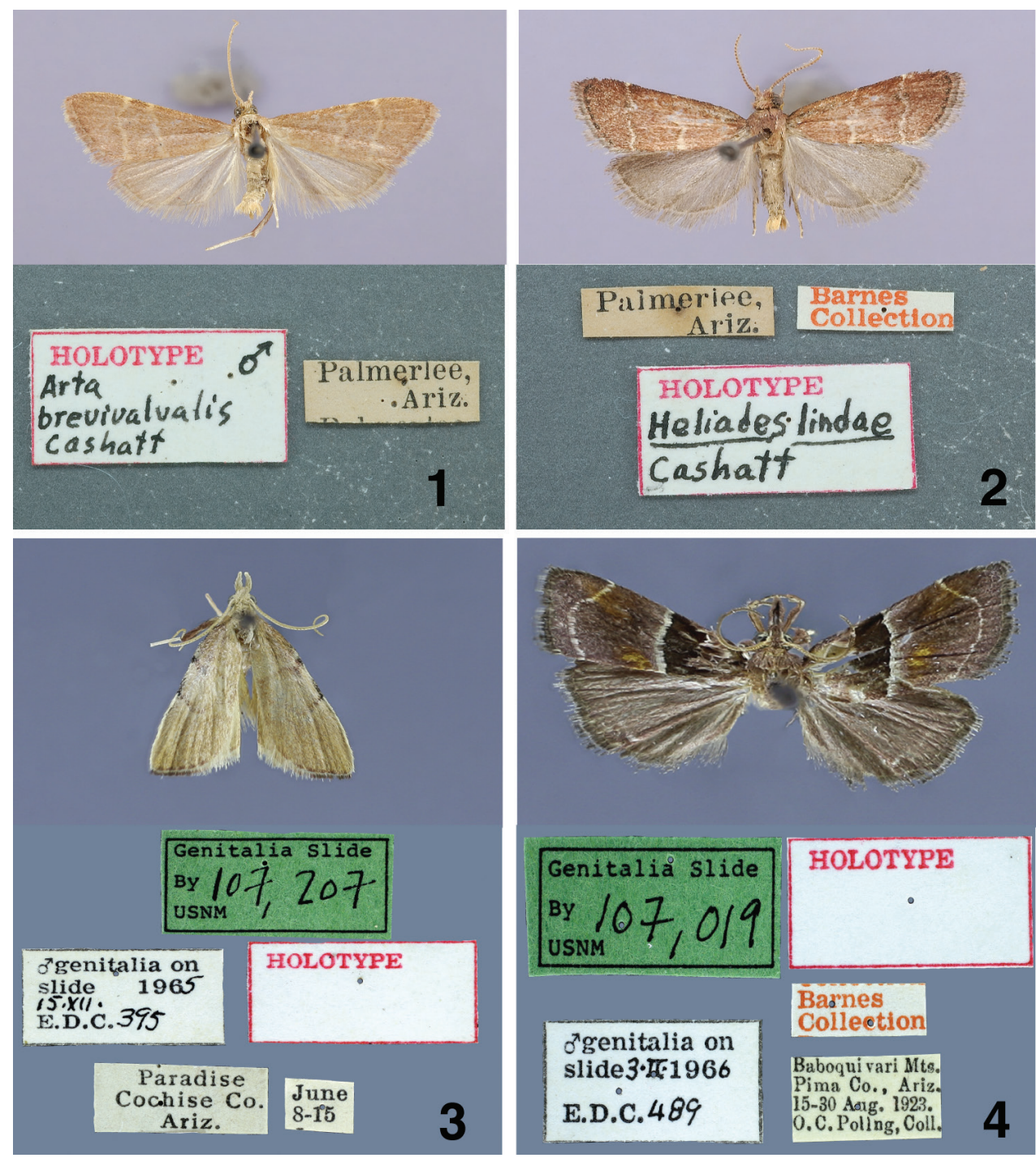

Figures I-4. Male holotypes of adults and labels. I Arta brevivalvalis 2 Heliades lindae $\mathbf{3}$ Paragalasa exospinalis 4 Penthesilea sacculalis baboquivariensis.

two males and two females, Catalina Mts., June 10, 1903, Oslar, Coll. (USNM); one female, Huachuca Mts., (USNM); one male, Madera Canyon, Santa Rita Mts., Aug. 18, 1953, Robert J. Ford (CNC); one male and one female, Madera Canyon, Santa Rita Mts., Aug. 19, 1953. Robert J. Ford (CNC); one male, Madera Canyon, Santa Rita Mts., Aug. 9, 1953 (CNC); one male, Palmerlee, Sept. 8-15 (USNM); twentyfive males and nine females, Palmerlee, no date given (USNM); seven males and four females, Ramsey Canyon, Huachuca Mts., Sept. 1-2, 1927, J. C. Bradley Coll. (CU); ten males and two females, White Mts., elevation $7200 \mathrm{ft}$., Aug. 1-15, 1925, Poling Coll. (USNM); one male and one female, White Mts., elevation 7200-11500 ft., Aug. 
10-30, 1925, O. C. Poling (USNM); three males, White Mts., Apache Co., near McNary P. O., Sept. 15-30, 1925, O. C. Poling.

Life history. Unknown.

Remarks. It is difficult to separate brevivalvalis from statalis and epicoenalis on the basis of maculation. The ochreous fringe is sometimes a useful diagnostic character but is not reliable. The distance between the antemedial and postmedial lines is variable.

An examination of the genitalia is necessary for accurate identification. The flattened and spade-shaped uncus of brevivalvalis easily separates this species from statalis and olivalis that have a narrow and more cylindrical shape. The valva of olivalis is long and slim. The uncus of epicoenalis is flattened, but not constricted at the base as in this species. The ostium bursae of brevivalvalis is broad compared to that of statalis, and the anterior apophyses are extremely short. The anterior apophyses of olivalis and epicoenalis are absent.

\section{Heliades lindae Cashatt, sp. n.}

http://zoobank.org/F91B3D1C-706B-4341-80C4-10AA5117497D

http://species-id.net/wiki/Heliades_lindae

Figs 2, 8-10

Description. Alar expanse. 15 to $17 \mathrm{~mm}$.

Head. Labial palpus dark reddish-brown with fuscous on under surface; frons, vertex, occiput, and antenna brownish-red.

Thorax. Upper surface brownish-red; under surface fuscous. Forewing brownishred with white dentate antemedial and postmedial lines; antemedial line extending from about two-fifths costa to nearly two-fifths inner margin, postmedial line extending from three-fourths costa to just proximad of anal angle; terminal line fuscous; fringe gray with a dark medial line; under surface grayish-brown with apex brownishred. Hind wing light grayish-brown; fringe gray with a dark medial line, under surface gray with apex reddish-brown. Legs fuscous with midtibia and tarsus white.

Abdomen. Upper surface concolorous with hind wings; terminal fringe ochreous.

Male genitalia. Uncus long and aculeate, setose dorsad; tegumen narrow dorsad; vinculum broad with a well-developed saccus, but more broadly rounded; gnathos reduced to a slender arm articulating at base of uncus; valva with sacculus small and papilliform, setose; valva heavily sclerotized and plate-shaped with apex truncate, ankylosed with flat truncate tips of arms produced by juxta; juxta shield-shaped and ankylosed with inner margin of vinculum; phallus long and slender, coecum welldeveloped.

Female genitalia. Ovipositor extremely short; apex of papillae anales bilobate and broad; eighth segment extremely short; anterior apophysis about one-half length of posterior apophysis; opening of ostium bursae at anterior of eighth sternite, small and sclerotized; anterior margin of sinus vaginalis bilobate and more broadly joined to the anterior margin of the eighth sternite; inception of ductus seminalis below antrum; 


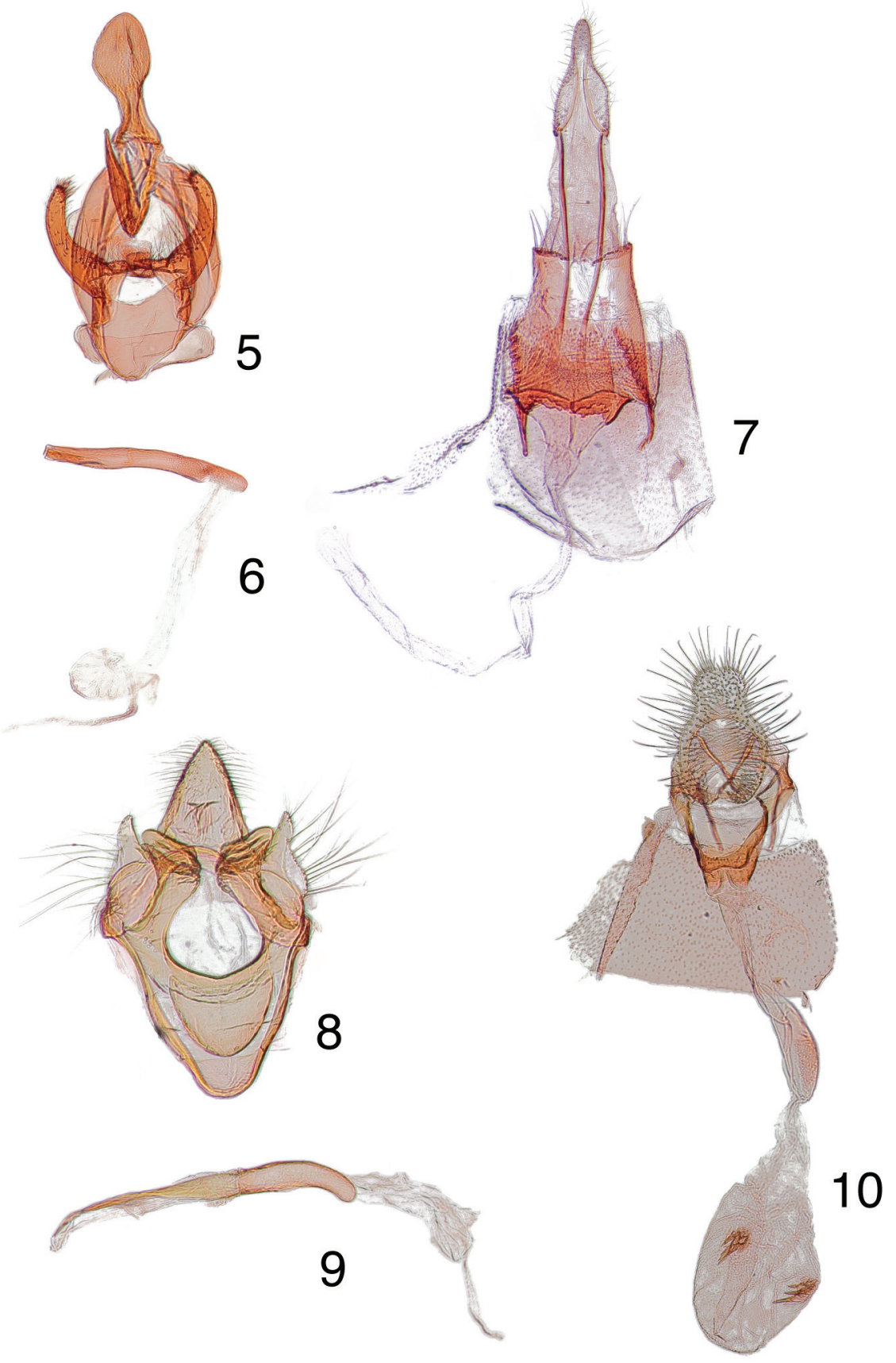

Figures 5-10. Male, female genitalia. 5 A. brevivalvalis paratype male, USA, Arizona, Palmerlee, [no collection date on label], EDC 981, USNM $104473 \mathbf{6}$ phallus, data same as previous 7 paratype female, USA, Arizona, Palmerlee, [no collection date on label], EDC 982, USNM 1044748 H. lindae paratype male, USA, Arizona, Palmerlee, [no collection date on label], EDC 80, USNM 1059939 phallus, data same as previous 10 paratype female, USA, Arizona, Palmerlee, [no collection date on label], EDC 84, USNM 104482. 
ductus bursae weakly sclerotized and constricted near junction of corpus bursae; signum a pair of spines.

Type data. All the type specimens are in the USNM. The male holotype is from Palmerlee, Arizona (no other data given) and is labeled as the holotype. Twenty-three male and nineteen female paratypes from UNITED STATES: ARIZONA are labeled as follows: one female, Baboquivari Mts., Pima Co., 1-15 Sept. 1923, O. C. Poling; one male, Chiricahua Mts., July 4, H. G. Hubbard; one male, Fort Grant, July 20, H. G. Hubbard; one female, Hereford, no date, C. R. Biedermann; one male, Huachuca Mts., no date; one female, Huachuca Mts., Aug. 8-15; one male, Madera Canyon, Santa Rita Mts., Aug. 19, 1953, Robert J. Ford; one male, Nogales, July 15, 1903, Oslar; one female, Oracle, July 28, 1924, E. P. Van Duzee; nine males, four females, Palmerlee, no date given; one female, Palmerlee, Cochise Co., Aug. 1-7; one male, one female, Paradise, Cochise Co., no date; four males, five females, Paradise, Cochise Co., July; two females, Paradise, Cochise Co., Aug.; one female, Paradise, Cochise Co., Aug. 1-7; one male, S.W.R.R., 5 mi. W. Portal, Cochise Co., 5400 ft., July 9, 1956, Cazier and Ordway; one female, Santa Catalina Mts., no date given; one male, White Mts., El. 7000 ft., July 15-22, 1925, O. C. Poling.

Life history. Unknown.

Remarks. It gives me pleasure to name this species in honor of my wife, Linda. The coloration of lindae is similar to huachucalis except the former is lighter and more reddish. The antemedial and postmedial lines of huachucalis are white, but unlike lindae the lines are margined with fuscous.

\section{Paragalasa Cashatt, gen. n.}

http://zoobank.org/E96A1722-5429-4294-9CCC-8A2727C56859

http://species-id.net/wiki/Paragalasa

Figs 3, 11-13

Paragalasa Cashatt, 1968, nomen nudum, Solis et al. 1995

Type species. Paragalasa exospinalis, Cashatt, new species.

Description. Head. Labial palpus porrect, length approximately equal to head width; maxillary palpus vestigial, two segmented, pilifers moderately developed; proboscis well developed; frons rounded with a tuft produced obliquely; vertex and occiput roughly scaled; ocellus immediately posteriad to base of antenna; chaetosema a row of fine setae along ocular sutura posteriad to ocellus.

Thorax. Forewing long and narrow, costa slightly incurved near middle, apex sublanceolate, outer margin rounded; sexually dimorphic: male with a small glandular vesicle at base of costa, discal cell shorter than in female, $\mathrm{R}_{1}$ not reaching costa, posterior angle obtuse; female without a glandular vesicle, $\mathrm{R}_{1}$ intercepting the costa, posterior angle of discal cell acute; both sexes with $S_{c}$ long, $\mathrm{R}_{1}$ arising from just before end of discal cell; $\mathrm{R}_{2}$ stalked short with $\mathrm{R}_{3}, \mathrm{R}_{4}$, and $\mathrm{R}_{5}$, stem arising from anterior angle of discal cell; $\mathrm{R}_{3}$ stalked with $\mathrm{R}_{4}$ and $\mathrm{R}_{5} ; \mathrm{R}_{4}$ and $\mathrm{R}_{5}$ coincident; $\mathrm{M}_{1}$ separate, arising from anterior angle of discal cell; male with $\mathrm{M}_{2}$ separate, $\mathrm{M}_{3}$ end $\mathrm{Cu}_{1}$ stalked short; $\mathrm{Cu}_{2}$ separate, arising 

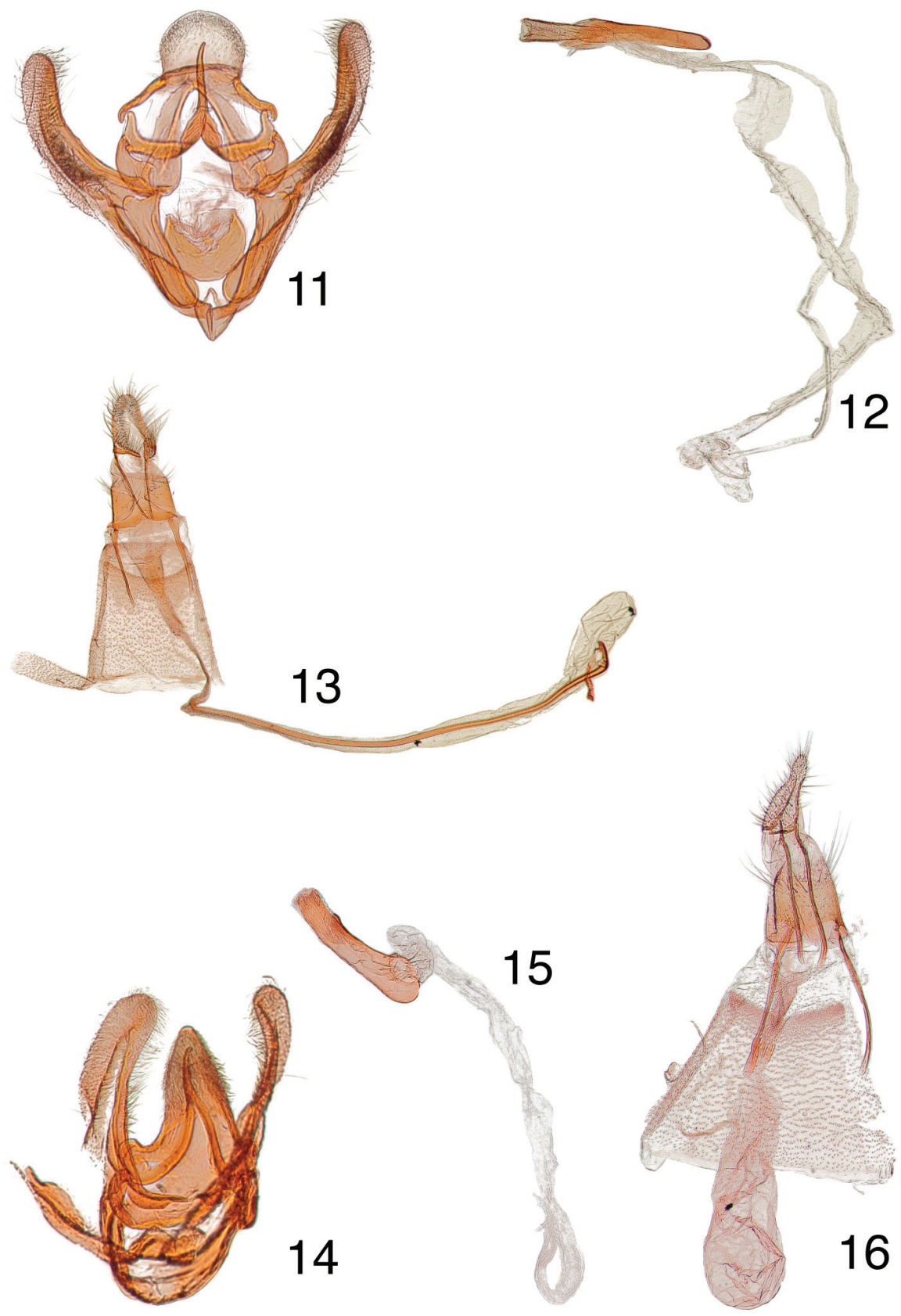

Figures I I-16. Male, female genitalia. I I Paragalasa exospinalis holotype male, USA, Arizona, Cochise Co., Paradise, June 8-15 [no year given], EDC 395, USNM 107207 I 2 phallus, data same as previous 13 paratype female, USA, Arizona, Redington, [no collection date on label], EDC 398, USNM 107089 14 Penthesilea sacculalis baboquivariensis holotype male, USA, Arizona, Pima Co., Baboquivari Mts., 15-30 Aug 1923, O.C. Poling, Coll., Barnes Collection, EDC 489, USNM 107019 I5 phallus, data same as previous 16 allotype female, USA, Arizona, Pima Co., Baboquivari Mts., [days crossed out] Aug 1924, O.C. Poling, Coll., Barnes Collection, EDC 138, USNM 100018. 
from posterior angle of discal cell; female $\mathrm{M}_{2}$ and $\mathrm{M}_{3}$ stalked short, $\mathrm{Cu}_{1}$ and $\mathrm{Cu}_{2}$ widely separated; $2 \mathrm{~A}$ and $3 \mathrm{~A}$ separate at base, anastomosed briefly a short distance from base; retinaculum normally developed. Hind wing frenulum normal; Sc and Rs anastomosed beyond end of discal cell; $M_{1}$ separate from anterior angle of discal cell; $M_{2}$ and $M_{3}$ short stalked from posterior angle of discal cell; posterior angle of discal cell extremely long and slender; $\mathrm{Cu}_{1}$ and $\mathrm{Cu}_{2}$ widely separated. Legs long, midtibia with two scale tufts.

Abdomen. Long and slender, without scale tufts.

Mala genitalia. Uncus moderately broad with apex rounded, slender arms from base modified to articulate with gnathos; tegumen narrow dorsad; pedunculus strongly modified for articulation with gnathal arms; vinculum moderately broad with saccus slightly produced; gnathos slender and aculeate, apex hooked dorsad; valva with sacculus distinct from valva, ventral margin of sacculus rounded; transtilla weak and incomplete; juxta with dorsal margin $\mathrm{V}$-shaped; phallus small, coecum long, apex with microspines, cornutus with spines short and spur-shaped.

Female genitalia. Ovipositor moderately long; papillae anales apex unilobate; anterior apophysis slightly longer than posterior apophysis; lamella postvaginalis triangulate; ostium bursae membranous, antrum lightly sclerotized, inception of ductus seminalis just below antrum; ductus bursae extremely long; corpus bursae small and without a signum.

Remarks. The venation and genitalia indicate a close relationship between this genus and Negalasa. The male Paragalasa has a small glandular vesicle at the base of the costa on the forewing, but is without a costal spur. The costa is straight. Negalasa and Galasa have a larger glandular vesicle, an incurved costal margin and a costal spur at the end of Sc. The uncus of Negalasa is more narrow and pointed, the tip of the valva is directed acutely mediad, and the phallus has a broadly rounded coecum and cornutus with long spines. The male genitalia of Paragalasa is similar to Galasa except the dorsal margin is $\mathrm{V}$-shaped, there is no process on the sacculus, and the phallus is smaller with a long cylindrical coecum and a small cornutus. The female Paragalasa has the inception of the ductus seminalis just below the antrum. The ductus bursae is extremely long with a small corpus bursae. Negalasa has the inception of the ductus seminalis more sclerotized, nearly two-thirds length from ostium bursae, and a large corpus bursae. The female venation of Paragalasa and Negalasa is identical. The male forewing of Negalasa shows more specialized structures.

\section{Paragalasa exospinalis Cashatt, sp. $\mathbf{n}$.}

http://zoobank.org/8B654928-5F29-4939-A494-E15FB480B90A

http://species-id.net/wiki/Paragalasa_exospinalis

Figs 3, 11-13

Paragalasa exospinalis Cashatt, 1968, nomen nudum, Solis et al. 1995

Description. Alar expanse. 19 to $22 \mathrm{~mm}$. 
Head. Labial palpus ochreous, darker laterad; frons, vertex, and occiput ochreous to tan; antenna ochreous.

Thorax. Upper surface pale reddish-brown, lower surface reddish-brown. Forewing pale reddish-ochreous; costa irrorated with fuscous, especially at base and at origin of antemedial and postmedial lines; antemedial line light reddish-brown, indistinct, extending from about one-third length of costa to about one-third length of inner margin; postmedial light reddish-brown and extending from about two-thirds length of costa sharply excurved to about two-thirds length of inner margin. Hind wing light pinkish to brownish-white with terminal line darker; fringe ochreous to brownish-ochreous. Legs ochreous, sprinkled with dark brown laterad, midtibia scale tufts fuscous.

Abdomen. Upper surface greyish-ochreous, fuscous laterad, lower surface ochreous.

Genitalia. As described for the genus.

Type data. All the type specimens in the USNM. The male holotype is from Paradise, Cochise Co., Arizona, June 8-15 and is labeled as the holotype. Twenty-six male and thirteen female paratypes from UNITED STATES: ARIZONA are labeled as follows: UNITED STATES: ARIZONA: eighteen males and two females, Baboquivari Mts., Pima Co., Ariz., elevation approximately 5000 ft., 15-30 June, 1923, O. C. Poling Coll.; four males, Brown's Canyon, Baboquivari Mts., Pima Co., Ariz., elevation approximately 5000 ft., 1-15 June 1923, O. C. Poling Coll.; one female, Brown's Canyon, Baboquivari Mts., Pima Co., Ariz., elevation approximately $5000 \mathrm{ft.}$, 15-30 May 1923, O. C. Poling Coll.; two females, Huachuca Mts., Ariz., no date given; three males and three females, Palmerlee, Arizona, no date given; one male, Paradise, Cochise Co., Ariz., June 8-15; one male, Paradise. Cochise Co., Ariz., July; one male and two females, Redington, Ariz., no date given; one female, Santa Rita Mts., Ariz., June 11, 1898. B. A. Schwarz.

Life history. Unknown.

Remarks. This species might be confused with Negalasa rubralis at first glance. Distinguishing characters are the fuscous antemedial and postmedial lines on the costa, generally lighter coloration, and the longer, more narrow forewings. The distinctness of the median band is variable.

\section{Penthesilea Ragonot, 1891}

http://species-id.net/wiki/Penthesilea

Figs 4, 14-16

Penthesilea Ragonot, 1891: 493.

Type species. Penthesilea sacculalis Ragonot, by monotypy.

Description. Head. Labial palpus decumbent; length of male palpus nearly equal to head width, length of female palpus longer than head width; maxillary palpus vestigial; proboscis moderately well-developed; frons rounded with vestiture extended 
obliquely; vertex smooth-scaled; occiput rough-scaled; eye large; ocellus separated from base of antenna by scales; without a chaetosema.

Thorax. Forewing broad and arched at base, apex broadly rounded, outer margin and anal angle broadly rounded; sexually dimorphic; male with a tympanic vesicle at base of costa, with a large hair-pencil gland as in Salobrena; female without a glandular vesicle; both sexes with Sc long, intercepting costa past one-half length; $R_{1}$ and $R_{2}$ separate; $R_{3}$ and $R_{4}$ stalked, $R_{5}$ from stem; $M_{1}$ from end of discal cell just below anterior angle; $M_{2}$ and $M_{3}$ separate and arising from posterior angle of discal cell; $\mathrm{Cu}_{1}$ and $\mathrm{Cu}_{2}$ separate and arising from below posterior angle of cell; $1 \mathrm{~A}$ absent, $2 \mathrm{~A}$ and $3 \mathrm{~A}$ separate at base but briefly anastomosed a short distance distad; retinaculum of male loop-shaped and strongly developed with inner surface corrugated as in Salobrena, Clydonopteron, Satole and Tosale. Hind wing of male with frenulum stoutly developed with a short hook at base, female normal; Sc arched at base and anastomosed with Rs past end of discal cell; $M_{1}$ arising from anterior angle of discal cell; $\mathrm{M}_{2}$ and $\mathrm{M}_{3}$ separate, arising from the posterior angle of discal cell; $\mathrm{Cu}_{1}$ and $\mathrm{Cu}_{2}$ separate, from before the posterior angle of the discal cell. Legs with scale tufts on mid and hind tibia.

Abdomen. Short and stout; male with a small lateral pleurite on the terminal segment bearing a tuft of scales as in Tosale and Salobrena.

Male genitalia. Uncus narrow, dorsally setose, aculeate with apex rounded, base with arms produced for articulation with gnathos, tips broadly rounded; vinculum narrow, saccus not produced anteriad; gnathos apex aculeate, gently curved dorsad, arms gradually expanded to broad articulation with modified pedunculus and base of uncus; valva narrow, tips directed slightly upward and mediad, sacculus without a clasping process; transtilla moderately developed and incomplete; juxta trapezoidal, dorsal margin concave; phallus slightly curved upward, proximal end slightly expanded, coecum small, without a cornutus.

Female genitalia. Ovipositor moderately short, apex of papillae anales unilobate; anterior apophysis slightly longer than posterior apophysis; lamella postvaginalis triangulate; anterior margin of eighth tergite rounded; ostium bursae membranous; a sclerotized constriction below antrum on ductus seminalis as in Tosale; inception of ductus seminalis at junction of ductus bursae and corpus bursae; corpus bursae without a signum.

Remarks. The genera Penthesilea and Tosale are closely related. The female genitalia have a membranous ostium bursae, a short sclerotized constriction on the ductus bursae, and the inception of the ductus seminalis at the junction of the ductus bursae and ostium bursae are common to both genera. Tosale differs in having the anterior margin of the eighth tergite heavily sclerotized. The male genitalia show more divergence. The uncus and valva of Penthesilea are more narrow than in Tosale and the saccus is not produced. Both genera have small lateral pleurites on the hind margin of the last abdominal segment of the male for support of lateral scale tufts. The venation indicates the Tosale is more specialized, with stalking of $\mathrm{R}_{2}, \mathrm{R}_{3}, \mathrm{R}_{4}$, and $\mathrm{R}_{5}$ in the forewing. The forewing of Penthesilea has $\mathrm{R}_{2}$ free with $\mathrm{R}_{3}$ and $\mathrm{R}_{4}$ stalked and $\mathrm{R}_{5}$ shortstalked. Both genera have $M_{1}$ widely separately from the stem of $R_{5}$. 


\section{Penthesilea sacculalis sacculalis Ragonot, 1891, revised status}

http://species-id.net/wiki/Penthesilea_sacculalis_sacculalis

Penthesilea sacculalis Ragonot, 1891: 493.

Description. Alar expanse. 13 to $16 \mathrm{~mm}$.

Head. Labial palpus dark brown with black; frons and vertex dark brown with white around the base of scape; occiput reddish-brown.

Thorax. Brown dorsad and ventrad. Forewing dark brown to fuscus; basal angle occasionally overscaled with reddish-brown, base darker than distal part; antemedial line white and slightly excurved; a yellow suffusion distad of white antemedial line; postmedial line white with a large brownish-orange suffusion near the costa, acutely excurved mediad; fringe fuscous. Hind wing dark brown to fuscous; $\mathrm{Cu}_{2}$ with a small white spot near outer margin, a small reddish-brown dash along $\mathrm{Cu}_{2}$ anteriad and posteriad to spot; fringe fuscous. Legs dark brown to fuscous; midtarsi white, hind tarsi white except first subsegment fuscous.

Abdomen. Brown overscaled with fuscous and reddish-brown, lateral tufts fuscous.

Genitalia. As described for genus.

Type data. One male holotype, with no locality data is in the Museum National D'Histoire Naturalle in Paris.

Material examined. Six males and eleven females from the following localities:

UNITED STATES: FLORIDA: Coconut Grove (USNM); Lake Placid, Archbold Bio. Sta., May (USNM); Royal Palm State Park (USNM); Winer Park [Winter Park?] (AMNH). GEORGIA: Atlanta (USNM). LOUISIANA: Lafayette, June (AMNH). NORTH CAROLINA: Southern Pines, July, Aug. (USNM). TEXAS: Brownsville (USNM); San Benito, July, Sept. (USNM). VIRGINIA: Skyland, July (USNM).

Life history. Unknown.

Remarks. Ragonot (1891) states that the type specimen is probably from North America. Of the specimens that I have examined, it more nearly matches the specimens from Florida. The specimens from Florida are darker and smaller than those from Louisiana, Texas, Georgia, and North Carolina.

\section{Penthesilea sacculalis baboquivariensis Cashatt, subsp. $\mathbf{n}$.} http://species-id.net/wiki/Penthesilea_sacculalis_baboquivariensis Figs 4, 14-16

Description. Alar expanse. 13 to $17 \mathrm{~mm}$.

Head. Labial palpus dark pinkish-brown; frons, vertex, occiput, and antenna pinkish-brown.

Thorax. Upper and lower surfaces pinkish-brown. Forewing same as the nominate species except pinkish-brown. Hind wing pinkish-brown occasionally with a small white spot as in sacculalis, but with no dark scaling anteriad or posteriad. Legs dark pinkish-brown with mid and hind tarsi white. 
Abdomen. Pinkish-brown with terminal scale tufts pinkish-brown.

Genitalia. As described for the genus.

Type data. The holotype, allotype, and forty-four paratypes are from the Baboquivari Mts., Pima Co., Arizona. The male holotype and female allotype are in the USNM. The male holotype is from Baboquivari Mts., Pima Co., Arizona, August 15-30, 1923, O. C. Poling, is labeled as the holotype, and the female allotype is labeled, August, 1924, O. C. Poling. The paratypes are labeled as follows: UNITED STATES: ARIZONA: two males and two females, elevation approximately $5000 \mathrm{ft}$., June 15-30, 1923 (USNM); one female, July 1-15, 1924, O. C. Poling (USNM); one female, July 15-30, 1924, O. C. Poling (USNM); two females, Aug. 1-15, 1924, O. C. Poling (USNM); one male and four females, Aug. 15-30, 1923, O. C. Poling (USNM); one male Aug., (USNM); three males and ten females, Sept. 1-15, 1923, 1924; O. C. Poling (USNM); one male and one female, Sept. 15-30, 1924, O. C. Poling (USNM); one male and four females, Oct. 1-15, 1923, O. C. Poling (USNM); one male and one female, Oct. 15-30, 1924, O. C. Poling (USNM); three males and two females, Sabino Canyon, Sept. 5-6, 1951, L. M. Martin (CNC); one male and one female, Sabino Canyon, Sept. 5, 1951, R. J. Ford (CNC).

Life history. Unknown.

Remarks. This subspecies differs from the nominal species only by the pinkishbrown coloration.

\section{Acknowledgments}

We thank Gary Ouellette, Terry Nuhn and Mark Metz, SEL, USDA for technical support to accomplish this project. Chris Thompson, retired, and Mark Metz, SEL, USDA, provided invaluable support with respect to the nomenclatural rules and provided suggestions for the manuscript. Paul Goldstein (University of Maryland), John Brown (SEL, USDA) and pyraloidologists Matthias Nuss, Museum für Tierkunde, Dresden, Germany, and James Hayden, Florida State Collection of Arthropods, Gainesville, Florida, provided suggestions that greatly improved the clarity of the manuscript.

\section{References}

Barnes W, McDunnough J (1917) Check list of the Lepidoptera of boreal America. Herald Press, Decatur, Illinois, 1-392. doi: 10.5962/bhl.title.10097

Cashatt ED (1968) Revision of the Chrysauginae of North America. Dissertation, Catholic University of America, Washington, D.C., 179 pp.

Cashatt ED (1969) Revision of the Chrysauginae of North America (Lepidoptera: Pyralidae). Dissertation, Abstracts International 29B: 4696. [abstract only]

Cashatt ED (1984) Revision of the genus Parachma Walker (Pyralidae: Chrysauginae) of North America north of Mexico with description of a new genus. Journal of the Lepidopterists' Society 38(4): 268-280. 
Fletcher DS, Nye IWB (1984) The generic names of the moths of the world. Pyraloidea 5. Trustees of the British Museum (Natural History), London, 185 pp.

Haimbach F (1915) New Heterocera (Lep.). Entomological News 27(7): 321-325.

Haman D, Huddleston RW (1980) Comments on the criteria of publication and a petition to the commission for a definitive ruling on the publication validity of dissertations et al. Z.N.(S.)2328. Bulletin of Zoological Nomenclature 37(3): 145-148.

Hampson G (1897) On the classification of the Chrysauginae, a subfamily of moths of the family Pyralidae. Proceedings of the Zoological Society of London 1897: 633-692.

International Commission on Zoological Nomenclature (1999) The International Code of Zoological Nomenclature. The International Trust for Zoological Nomenclature, London $306 \mathrm{pp}$.

Landis DA, Sorenson CE, Cashatt ED (1992) Biology of Clydonopteron sacculana (Lepidoptera: Pyralidae) in North Carolina, with description of the egg stage. Annals of the Entomological Society of America 85(5): 596-604.

McDunnough J (1939) Check list of the Lepidoptera of Canada and the United States of America, Part II, Microlepidoptera. Memoirs of the Southern California Academy of Sciences 2(1): 1-171.

Miller SE, Becker VO (1989) North American moths described by L.A.G. Bosc D’Antic Lepidoptera Noctuidae Pyralidae. Proceedings of the Entomological Society of Washington 91: $22-25$.

Munroe EG (1983) Pyralidae (except Crambinae). In: Hodges RW, Dominick T, Davis DR, Ferguson DC, Franclemont JG, Munroe EG, Powell JA (Eds) Check List of the Lepidoptera of America North of Mexico. E. W. Classey and The Wedge Entomological Research Foundation, London, 67-85.

Ragonot EL (1891) Essai sur la classification des Pyralites. Annales Société Entomologique de France 1890: 489-546.

Riley CV (1880) On a new pyralid infesting the seed pods of the trumpet vine. American Entomologist 3: 286-288.

Solis MA, Becker VO, Munroe EG (1995) Chrysauginae. In: Heppner JB (Ed) Checklist: Atlas of Neotropical Lepidoptera. Association of Tropical Lepidoptera, Gainesville, Florida, 80-105. 